children. 'Backlash' has influenced American paediatricians' willingness to report abuse. More accurate recording of findings including photographs will help.

1 Hobbs CJ, Wynne JM, Thomas AJ. Colposcopic genital findings in prepuber sexual abuse. Arch Dis Child 1995; 73: 465-71.

2 Adams JA, Harper K, Knudsen S, Revilla J Examination findings in legally confirmed child sexual abuse. It's normal to be normal Pediatrics 1994; 94: 310-7.

3 McCann J, Wells R, Simon M, Voris J. Genital findings in prepubertal girls selected for non findings in prepubertal girls selected for non
abuse: a descriptive study. Pediatrics 1990; 86: abuse: a

4 Berenson AB, Hegor AH, Hayes JM, Bailey RK, Emans SJ. Appearance of the hymen in prepubertal girls. Pediatrics 1992; 89: 387-94.

5 Lillibridge C, Kappes B. Quantitative observations of hymens in prepubescent females selected for non-abuse. Alaska Med 1993; 35: 160-7.

6 Berenson AB. A longitudinal study of hymenal morphology in the first 3 years of life. Pediatrics 1995; 95: 490-6.

7 Hobbs CJ, Wynne JM. Physical signs of child abuse. $A$ colour atlas. London: WB Saunders, 1996.

8 Royal College of Physicians. Physical signs of sexual abuse in children. A report of the Royal
College of Physicians. London: Royal College of Physicians, 1991.

\section{A new clinical sign in Williams syndrome}

EDrToR,-Williams syndrome is a well recognised condition with typical facies, supravalvular aortic stenosis, mental retardation, and a characteristic personality. ${ }^{1}$ In a large series $(n=235) 96 \%$ of patients demonstrated a deletion of the elastin gene from the long arm of chromosome $7 .^{2}$ Strabismus is common in Williams syndrome ${ }^{3}$ and this may contribute to subnormal binocular vision and reduced stereopsis. In a recent study of 28 patients with typical features and deletion of the elastin gene an interesting sign was noted. On further inquiry it was found to have been present in $30 \%(n=9)$ of cases. The observation is that as children they have a great reluctance in changing the surface on which they are walking or playing. A typical example would be going from a tiled to a carpeted surface. The child would stop at the interface and refuse to proceed. They may then feel out the new surface with either a probing foot or in some cases descend to all fours to confirm the suitability of the next surface. The process of transfer may take several minutes. Parents describe this observation in both indoor and outdoor settings. It would seem that there is a problem in determining depth perception when there is either a new pattern or colour to the surface. A reluctance to proceed may reflect a fear of falling to the next surface. Similar difficulties are experienced in attempts to descend stairs. Another interesting observation in this group is an intense dislike by these children of sandy surfaces. This is most likely an extension of the previous observation in that this surface is undulating, has a variable visual pattern, and conveys a sinking feeling that contributes to the uncertainty of the surface. Several of the children experienced great distress when faced with this circumstance. As the children grow older the problem diminishes and most have fewer concerns in changing surfaces by 8 years of age.

This clinical sign has not been described previously in this group and I am unaware of any other paediatric group who demonstrate a similar sign. I would be most pleased to hear from any other groups who may have made similar observations.
STEPHEN WITHERS

Queensland Clinical Genetics Service,

Royal Children's Hospital, Brisbane,

Herston Road, Herston,

Queensland 4029,

Australia

1 Morris CA, Demsey SA, Leonard CO, Dilts C, Blackburn BL. Natural history of Williams syndrome: physical characteristics. If Pediat 1988; 113: 318-26.

2 Lowery MC, Morris CA, Ewart A, et al. Strong correlation of elastin deletions, detected by correlation of elastin deletions, detected by 235 patients. Am f Hum Genet 1995; 57: 235 pa.

3 Kapp ME, von Noorden GK, Jenkins $R$ Strabismus in Williams syndrome. Am $\mathcal{F} O p h-$ thalmol 1995; 119: 355-60.

\section{Calculation of the need for paediatric} intensive care beds

EDrToR,-While we support efforts to correct the country's deficiencies in paediatric intensive care and we applaud Milne and Whitty's academic approach to the issue, we feel compelled to comment on their paper.

The use of a model that matches patterns of use of intensive care in a fragmented or decentralised intensive care delivery system cannot help determine the true bed requirement of a centralised system. Because the authors fail to acknowledge the improved efficiency of larger intensive care units in terms of duration of admission, their model overestimates the numbers of beds required by a given population under such circumstances.

Most importantly we should emphasise that measures of the efficiency of paediatric intensive care are not restricted to economics or length of stay. The evidence that centralised paediatric intensive care facilities decrease mortality is very convincing. In the UK we have collectively failed to adequately recognise and address these issues, despite the BPA report and its reviews (referenced in the article). We therefore have to accept the risk of morbid and mortal consequences.

G A PEARSON

CHARI ES RAISTON Paediatric Intensive Care Unit, Birmingham Children's Hospital, Ladywood Middleway

Ladywood, Birmingham B16 8ET

\section{Drs Milne and Whitty comment:}

The purpose of our paper was to draw attention to the striking similarity between estimates of paediatric intensive care bed need made by different authors working in different health care systems, with different population sizes, and one would assume, with different levels of efficiency. We would certainly not conclude from our data that we had identified the correct level of paediatric intensive care provision, but have rather sought to identify a currency with which debate can properly take place. The comments of Drs Pearson and Ralston on the efficiency of larger intensive care units reflect the views of Shann cited in the discussion of our paper. The importance of intensive care in reducing mortality and morbidity is one that we would not dispute, but again this was not the focus of our article.

Milne E, Whitty P. Calculation of the need for paediatric intensive care beds. Arch Dis Child paediatric inten

\section{2q11 deletion: a cause of asymmetric crying facies}

EDITOR,-We agree with Hamish et al that permanent facial asymmetry in the newborn has many causes. ${ }^{1}$ Facial asymmetry present only on crying has been described as a separate entity and termed asymmetric crying facies (ACF). ${ }^{2}$ ACF is due to hypoplasia of the depressor anguli oris muscle ${ }^{3}$ and has been described in association with congenital heart disease as cardiofacial syndrome. ${ }^{4}$ This syndrome may include abnormalities of other systems and may be inherited in an autosomal dominant manner with variable expression.

We also agree with Trainer et al that microdeletions of chromosome 22q11 detected on fluorescent in situ hybridisation (FISH) are responsible for a wide range of clinical presentations including cardiac abnormalities. ${ }^{5}$ Five patients with cardiofacial syndrome have been found to have a microdeletion of chromosome $22 \mathrm{q} 11$. $^{\circ}$

We have recently seen an 8 year old girl who presented with ACF without cardiac abnormalities who had 22q11 deletion demonstrated on FISH. This is the first such case and we believe that this represents a further expansion of both the differential diagnosis of facial asymmetry in the newborn and the 22q11 phenotype.

H S STEWART J CLAYTON-SMITH Hathersage Manchester M13 OfH

1 Hamish J, Laing E, Harrison DH, Jones BM, Laing GJ. Is permanent congenital facial palsy caused by birth trauma? Arch Dis Child 1996; 74: 56-8.

2 Hoefnagel D, Penry JK. Partial facial paralysis in young children. $N$ Engl $\mathcal{F}$ Med 1960; 262: 1126-8.

3 Nelson KB, Eng GD. Congenital hypoplasia of the depressor anguli oris muscle: differentiation from congenital facial palsy. $₹$ Pediatr tion from congeni

4 Cayler GG. Cardiofacial syndrome. Congenital heart disease and facial weakness, a hitherto heart disease and facial weakness, a hitherto unrecognised

5 Trainer AH, Morrison N. Dunlop A, Wilson N, Tolmie J. Chromosome 22q11 microdeletions in tetralogy of Fallot. Arch Dis Child 1996; 74: 62-3.

6 Giannotti A, Mingarelli R. Cayler cardiofacia syndrome and del 22q11: part of the CATCH 303-4.

Expulsion of ventriculoperitoneal shunt tubing

EDITOR,-In reply to the letter by Dr Swann on the supposedly unique occurrence of expulsion of ventriculoperitoneal shunt tubing, ${ }^{1}$ I would like to describe another case, not of expulsion but extrusion of ventriculoperitoneal tubing per rectum.

A first twin born by caesarean section on our delivery unit at 26 weeks' gestation had a stormy neonatal course complicated by posthaemorrhagic hydrocephalus. He subsequently needed a ventriculoperitoneal shunt.

He was readmitted at the chronological age of 4.5 months with irritability, fever, and swelling over the shunt site. He was suspected of having a shunt infection and was treated with intravenous cefotaxime and flucloxacillin. After 24 hours in hospital the nursing staff noticed, while changing his nappy, extrusion of the shunt per rectum.

$\mathrm{He}$ was immediately transferred to the neighbouring neurosurgical unit who were somewhat peeved that we had not put a 'clip' on the free end-it had disappeared back up into the abdominal cavity. He grew Escherichia coli from the cerebrospinal fluid and 
shunt assembly and when appropriate had a reinsertion of his ventriculoperitoneal shunt. He remains well.

FRANCES LATCHAM
Hinchingbrooke Hospital,
Huntingdon,

1 Swann IL. Expulsion of ventriculoperitoneal shunt tubing. Arch Dis Child 1996; 74: 184.

EDITOR,-I was fascinated by Ian Swann's report of the patient passing per rectum the lower distal portion of a ventriculoperitoneal shunt. ${ }^{1}$ Although unreported, when I was a registrar in paediatric neurology at the Royal Hospital for Sick Children in Edinburgh, I was called by the nurses to see what they described as a worm having been passed into the nappy of a child with hydrocephalus. The young boy was completely asymptomatic, but on closer inspection we realised that this was a tube protruding from the baby's anus. Under gentle pressure the full length of the distal component of the shunt came away. At no time did he develop any further symptoms or signs unlike the reported patient. Although ventriculoperitoneal shunts not infrequently cause some local peritoneal inflammation or infection, such expulsion is obviously rare, but sadly not quite as unique as the case report implied.

O B EDEN

Christie Hospital NHS Trust, Wilmslow Road, Withington, Manchester M20 4BX

1 Swann II. Expulsion of ventriculoperitoneal shunt tubing. Arch Dis Child 1996; 74: 184.

\section{The effect of a child's disability on a mother's mental health}

EDrToR,-Have Dr Lambrenos and colleagues considered the possibility that the research process itself might have prevented some cases of depression? ${ }^{1}$ Firsly, before discharge from hospital the explanation given to the mothers of babies with abnormal ultrascans may have accelerated the grieving process involved in accepting a child with a disability, and prepared the mothers for cop- ing in the future. Secondly, the interviews by the research psychologist, although intended to be for assessment only, may have been therapeutic. A close, supportive relationship can develop between researchers and their subjects, and the unintended benefits to patients of involvement in a research trial have been noted before. ${ }^{2}$ It is possible that the opportunity to talk helped mothers cope with any feelings they had about their children's prematurity or potential disability, but did not alter the emotional consequences of psychosocial adversity. If this were the case, this apparently very well designed study could have inadvertently prevented the depressive disorder it was meant to detect.

QUENTIN SPENDER Department of General Psychiatry, Child and Adolescent Psychiatry Section, St George's Hospital Medical School, Cranmer Terrace, Tooting,

London SW17 ORE

\section{Dr Lambrenos comments:}

It is always possible, as Dr Spender points out, that the mothers in the study derived support from the research assessments. However, the research interview was wide ranging and did not focus on disability. Furthermore mothers of infants receiving the early physiotherapy intervention received much more professional support in addition to the research interviews. If talking about disability helped them to cope one would have expected to detect lower levels of depression in this group. These were not found. Up until the 12 month assessment only low levels of disability were evident. The mothers, rather than grieving, were relatively optimistic, and seemed to be denying the news broken to them on the neonatal intensive care unit. Perhaps grieving is a task to be negotiated by the mothers during the second year of their children's lives, when disabilities are evident.

1 Lambrenos $\mathrm{K}$, Weindling AM, Calam R, Cox $\mathrm{AD}$. The effect of a child's disability on mother's mental health. Arch Dis Child 1996; 74: er's mental

2 Reiser J, Wamer JO. The value of participating in an asthma trial. Lancet 1985; i: 206-7.
Thalidomide treatment of mucosal ulcerations in HIV infection

EDITOR,-The case report by Solèr and colleagues confirms the beneficial effects of thalidomide in treating aphthous ulcers in HIV/AIDS patients unresponsive to conventional treatments including oral prednisolone. ${ }^{1}$ One important side effect encountered in our centre and reported by others ${ }^{2}$ is irreversible peripheral neuropathy associated with prolonged high dose in patients with relapsing aphthous ulcers. Patients should be counselled about this as well as, of course, the teratogenic potential in females at risk of pregnancy.

TUBONYE C HARRY

Department of Genitourinary Medicine, Sunderland District General Hospital, Sunderland SR4 7TP

1 Solèr RA, Migliorati C, van Waes H, Nadal D. Thalidomide treatment of mucosal ulcerations in HIV infection. Arch Dis Child 1996; 74: 64-5.

2 Sophie D, Josette V, Bastuji-Garin S, Romain G, Jean $R$. Thalidomide neuropathy incidence and clinicoelectrophysiologic findings in 42 patients. Arch Dermatol 1994; 130: 66-9.

\section{Infant length measurements}

EDITOR,-Dr Falkner rightly commends the use of infant length measurements. ${ }^{1}$ But the available standards for length velocity must be treated with caution; some of these (including that quoted in Dr Falkner's letter) are derived from smoothed rather than observed data points and are thus liable to produce centiles which are too close together. ${ }^{2}$ The same caveat applies to some of the published standards for fetal growth velocities.

M J R HEALY 23 Coleridge Court, Milton Road, Harpenden AL5 SLD

1 Falkner F. Infant length measurements. Arch Dis Child 1995; 73: 379.

2 Royston P. Calculation of unconditional and conditional reference intervals for foetal size and growth from longitudinal measurements. Stat Med 1995; 14: 1417-36. 